\title{
Height as a risk factor in meningioma: a study of 2 million Israeli adolescents
}

\author{
Matan Ben-Zion Berliner ${ }^{1^{*}}$ (D), Lior Haim Katz ${ }^{2}$, Estela Derazne ${ }^{3}$, Hagai Levine ${ }^{4}$, Lital Keinan-Boker, ${ }^{5,6}$, \\ Alexandra Benouaich-Amiel ${ }^{1}$, Omer Gal ${ }^{1,3}$, Andrew A Kanner ${ }^{3,7}$, Yosef Laviv ${ }^{3,7}$, Asaf Honig ${ }^{8}$, Tali Siegal' ${ }^{1}$, \\ Jacob Mandel ${ }^{8}$, Gilad Twig ${ }^{3,8,9}$ and Shlomit Yust-Katz ${ }^{1,3}$
}

\begin{abstract}
Background: Meningiomas are the most common primary central nervous system tumors. Potential risk factors include obesity, height, history of allergy/atopy, and autoimmune diseases, but findings are conflicting. This study sought to assess the role of the different risk factors in the development of meningioma in adolescents/young adults.

Methods: The cohort included 2,035,915 Jewish men and women who had undergone compulsory physical examination between 1967 and 2011, at age 16 to 19 years, prior to and independent of actual military enlistment. To determine the incidence of meningioma, the military database was matched with the Israel National Cancer Registry. Cox proportional hazard models were used to estimate the hazard ratios for meningioma according to sex, body mass index (BMI), height, and history of allergic or autoimmune disease.

Results: A total of 480 subjects (328 females) were diagnosed with meningioma during a follow-up of 40,304,078 person-years. Median age at diagnosis was $42.1 \pm 9.4$ years (range 17.4-62.6). On univariate analysis, female sex ( $p<$ $0.01)$ and height $(p<0.01)$ were associated with risk of meningioma. When the data were stratified by sex, height remained a significant factor only in men. Spline analysis of the male subjects showed that a height of $1.62 \mathrm{~m}$ was associated with a minimum disease risk and a height of $1.85+$ meters, with a significant risk.
\end{abstract}

Conclusions: This large population study showed that sex and adolescent height in males (>1.85 m) were associated with an increased risk of meningioma in adulthood.

Keywords: Allergy, Autoimmune disease, Height, Meningioma, Sex

\section{Background}

Meningiomas are the most common primary central nervous system tumors. They originate from the meninges which are the membranous layers surrounding the brain. Most meningiomas (80-90\%) are grade I (benign); $10-15 \%$ are grade II (atypical), and $1-3 \%$ are grade III (anaplastic) [1]. Benign meningiomas have a female predominance $(2: 1$ or $3: 1)$ which is not found in the more

\footnotetext{
* Correspondence: matanbe4@gmail.com

${ }^{1}$ Neuro-Oncology Unit, Davidoff Cancer Center, Rabin Medical Center Beilinson Hospital, Petach Tikva, Israel

Full list of author information is available at the end of the article
}

aggressive types [1]. In the USA, meningiomas were found to be more common in blacks than in whites, with a ratio of 1.2:1 [2]. The risk of acquiring a meningioma increases with age. The median age at diagnosis is 65 years [1].

The only established external (non-genetic) risk factor for brain tumors is exposure to ionizing radiation [3]. An Israeli study revealed abnormally high rates of meningioma in patients treated with low-dose radiation to the scalp for tinea capitis during the 1950s [4]. Other potential risk factors include obesity, height, history of allergy/atopy, and history of autoimmune diseases, but 
the results are conflicting [5-10]. Establishing risk factors for meningioma can help identify individuals who might benefit from risk reduction strategies and possibly early screening methods.

The aim of the present study was to assess potential risk factors for the development of meningioma in adolescence and early adulthood.

\section{Methods}

\section{Study population}

Israeli adolescents undergo a compulsory medical examination at age 17 to assess their fitness for military service (regardless of whether they are drafted or not). Arab and Orthodox Jewish females and males and Druze females are exempted. Together with the physical examination, sociodemographic and psychobehavioral data are collected, and the medical history is thoroughly reviewed using documents provided by each subject's primary care physician. At the end of the process, recruits are assigned a Functional Classification Code (FCC) that describes their medical status and occupational medical ranking. The medical data and FCC are stored in the army's main database which was computerized in 1967 [11].

The population for the present study was derived from 2,285,456 subjects born in 1948-1991 who underwent pre-enlistment medical examination between 1967, when the database was computerized, and 2011 (at age 16-19 years). Subjects with missing data on height and weight were excluded $(n=56,683)$. We also excluded 192,858 subjects of North African and Asian origin born before 1960, many of whom had been exposed to radiation for the treatment of tinea capitis after immigrating to Israel during the 1950s [12]. These communities were later found to have a particularly high rate of meningioma [4]. The final cohort consisted of 2,035,915 subjects (Fig. 1).

Records were reviewed from the date of the initial medical examination for military fitness to the date of a first diagnosis of any cancer, death, or the predetermined end of follow-up (December 31, 2012).

\section{Study variables}

At the pre-enlistment medical examination, demographic variables for each recruit were recorded in the army database as follows: date of birth, age at examination, country of origin, education, socioeconomic status, height, weight, and body mass index (BMI). Origin was defined by father's country of birth or, if the examinee's father was born in Israel, by paternal grandfather's country of birth, and categorized as Europe (including North and South America, Australia, and Southern Africa), Asia (predominantly the Middle East), Africa (overwhelmingly North Africa), and Israel (third or later generation). Education was categorized as $\leq 9,10,11$,

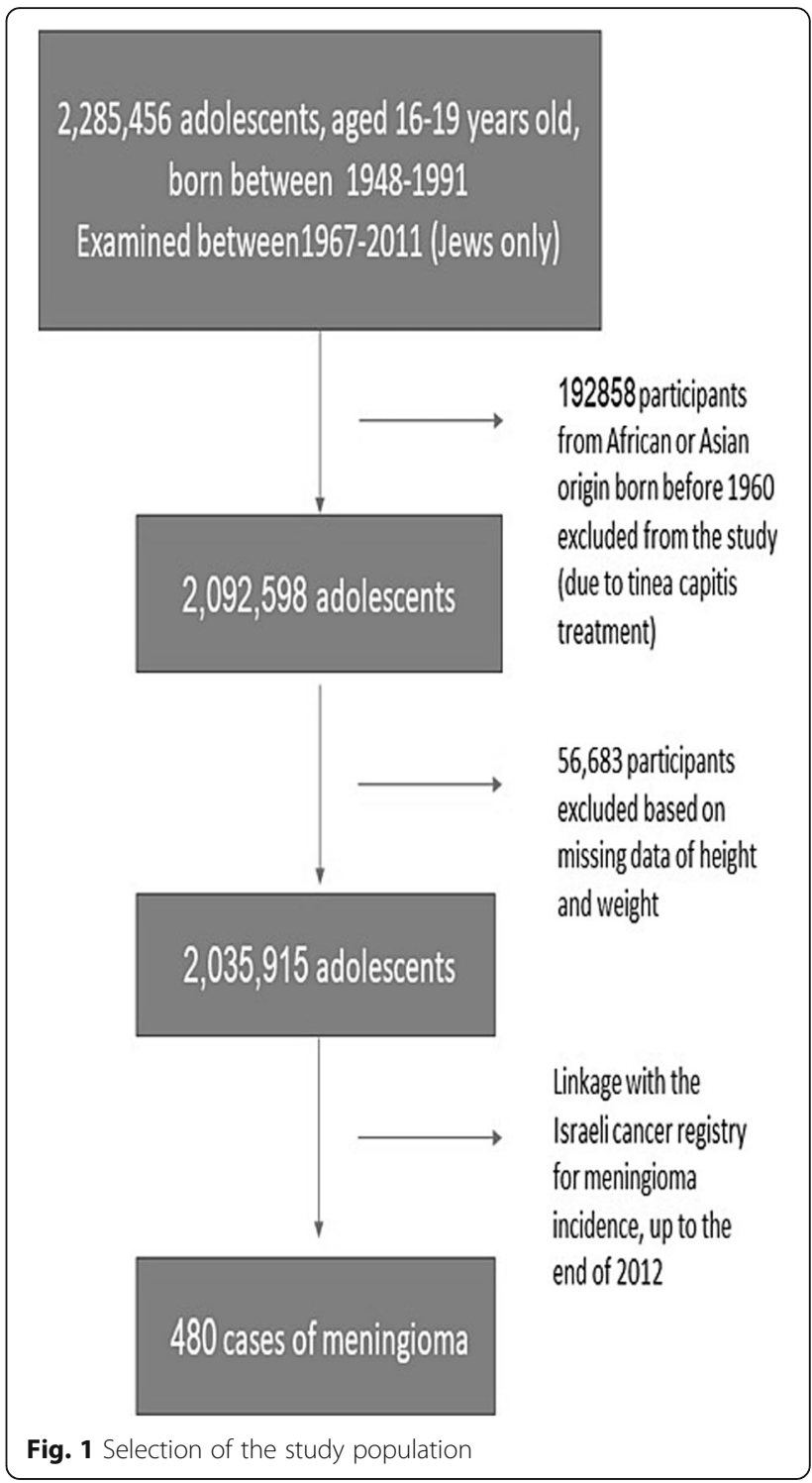

and $\geq 12$ years of schooling. Socioeconomic status was determined by place of residence at the time of examination, coded on a scale of $1-10$, and categorized into low (score 1-4), middle (score 5-7), and high (score 8 10) [13]. Height and weight were measured by trained medics using a stadiometer and a beam balance, with examinees barefoot and in underwear. BMI was calculated as weight (in kilograms) divided by height squared (in meters) and categorized according to the $\mathrm{WHO}$ as underweight $\left(<18.5 \mathrm{~kg} / \mathrm{m}^{2}\right)$, healthy weight $(18.5-24.9$ $\left.\mathrm{kg} / \mathrm{m}^{2}\right)$, overweight $\left(25.0-29.9 \mathrm{~kg} / \mathrm{m}^{2}\right)$, and obese $(\geq 30.0$ $\mathrm{kg} / \mathrm{m}^{2}$ ). Height was categorized according to the Centers for Disease Control and Prevention: below 25th percentile, 25 th to 50 th percentile, 50th to 75 th percentile, and 75th percentile and above.

Cognitive function, including language skills and intellectual performance [11], was assessed by a general 
intelligence test administered by trained personnel. The test is scored on a 90-point scale that is adjusted from time to time; scores are categorized as low (10-30), medium (40-70), and high (80-90) [14].

Medical history was assessed according to the FCCs. Autoimmune diseases (diabetes mellitus, lupus, vasculitis, inflammatory bowel disease, pemphigus, thyroid disease, celiac, rheumatoid arthritis, Addison disease and idiopathic thrombocytopenia purpura) and allergic diseases (asthma, urticaria, eczema, allergic rhinitis, atopic dermatitis, allergic conjunctivitis, and anaphylaxis) were grouped together for the present analysis.

\section{Ascertainment of meningioma incidence}

To determine the incidence of meningioma, we matched the subjects who underwent the pre-enlistment medical examination during the study years, to the Israel National Cancer Registry (INCR), a national, populationbased registry established in 1960. In 1982, Israeli law mandated the reportage of all diagnoses of malignant (in situ and invasive), borderline and certain benign (brain and central nervous system) tumors. The estimated rate of reportage for solid tumors is $97 \%$, which meets the standards of the International Association of Cancer Registries (https://www.health.gov.il/PublicationsFiles/ ICDC_365_EN_summary.pd). The INCR data include the date of diagnosis, site affected, the International Classification of Diseases code, and the histologic description of the tumor according to the third edition of the International Classification of Diseases for Oncology (ICD-O-3 codes 9350, 95,301, 95,303, 95,310, 95,320, 95, $330,95,340,95,370,95,383$, and 95,391). At the time of matching, the INCR had been updated until the end of 2012.

\section{Statistical analysis}

Categorical variables are presented as number and percentage, and continuous variables, as mean and standard deviation (SD); median 25th and 75th percentiles, minimum, and maximum were also calculated. The association between risk factors and time to meningioma diagnosis was assessed using Cox proportional hazard models; hazard ratios (HR), 95\% confidence intervals (95\% CI), and $p$-values were calculated. Log minus log figures were inspected to confirm the proportionality of the hazard. Crude rates were also determined. Independent variables were initially entered individually into the Cox model. After sex and the interaction of sex and height were found to be statistically significant, separate models were established for men and women. A Cox regression cubic spline function with three equally spaced knots positioned between the minimum and maximum values of height was fit to the data to estimate the height value associated with minimum risk of meningioma in men (SAS/STAT and SAS/GRAPH software, version 9.4, SAS Institute Inc., Cary, NC, USA). Other statistical analyses were performed with SPSS Statistics for Windows, version 24.0 (IBM, Armonk, NY, USA). Two-sided $p$ values of $\leq 0.05$ were considered statistically significant.

\section{Results \\ Study population}

The baseline characteristics of the study population are presented in Table 1. The mean age at initial examination was $17.4 \pm 0.4$ years; $41.7 \%$ of the cohort was female. The mean duration of follow-up was $19.8 \pm 10.5$ years (median 18.5) which represent in this study population a follow up of 40,304,078 person-years. The characteristics of the medical history of the subjects are presented in the supplementary table (Table 1S).

Linkage of the military database with the INCR yielded a diagnosis of meningioma in 480 of the 2,035,915 subjects who underwent medical examination in 1967 to 2011, at age 16-19 years: 228 grade I, 27 atypical, 5 anaplastic, 219 not specified and one patient with meningiomatosis (Table 2). The mean age at diagnosis of meningioma was $42.1 \pm 9.4$ years (range 17.4-62.6), and at the end of follow-up, $37.2 \pm 10.6$ years (median 35.9 ).

\section{Univariate analysis}

Overall, as expected, meningiomas were more common in females (328 cases, crude rate 2.0 per 100,000 person years) than in males ( 152 cases, crude rate 0.63 per 100 , 000 person-years $(p<0.001$, HR 3.43 CI $2.84-4.17)$. However, there was no sex difference in the incidence for the more aggressive meningiomas, atypical and anaplastic (crude rate $=0.08$ per 100,000 person-years for males and females). On univariate analysis, only sex and height were significantly associated with the risk of meningioma in the whole study population ( $p<0.01$ for both variables). After stratification by sex, height remained significant only in males (Table 3). The risk of meningioma was minimal when height was up to $1.62 \mathrm{~m}$ and statistically significant when height was greater than $1.85 \mathrm{~m}$ (Fig. 2). BMI was not associated with an elevated risk of meningioma even when analyzed separately by sex (Table 3 ).

Past medical history of asthma, diabetes, and other atopic or autoimmune diseases was not associated with risk of meningioma. Even when autoimmune and allergic diseases were analyzed as a group, there was no association with lower risk of meningioma (Table 3 and Supplemental Table 2).

When the subjects of African and Asian origin who were excluded from the main analysis were included in the cohort, there was a significant interaction between period of birth (1948-1959 vs 1960-1971) and Asian and African origin (representing the Middle East and North Africa) as opposed to European and Israeli origin. 
Table 1 Baseline characteristics of the study population, total and by sex

\begin{tabular}{|c|c|c|c|c|c|c|c|}
\hline \multirow[t]{2}{*}{ Characteristics } & & \multicolumn{2}{|l|}{ Male } & \multicolumn{2}{|l|}{ Female } & \multicolumn{2}{|l|}{ Total } \\
\hline & & Number & $\%$ & Number & $\%$ & Number & $\%$ \\
\hline \multirow[t]{5}{*}{ Birth year } & Total & $1,187,421$ & 100.0 & 848,494 & 100.0 & $2,035,915$ & 100.0 \\
\hline & $1948-59$ & 117,428 & 9.9 & 69,703 & 8.2 & 187,131 & 9.2 \\
\hline & 1960-69 & 256,934 & 21.6 & 166,744 & 19.7 & 423,678 & 20.8 \\
\hline & 1970-79 & 358,090 & 30.2 & 260,927 & 30.8 & 619,017 & 30.4 \\
\hline & 1980-91 & 454,969 & 38.3 & 351,120 & 41.4 & 806,089 & 39.6 \\
\hline \multirow[t]{3}{*}{ Socioeconomic status } & Low & 312,671 & 26.5 & 174,640 & 20.7 & 487,311 & 24.1 \\
\hline & Medium & 609,644 & 51.7 & 456,821 & 54.1 & $1,066,465$ & 52.7 \\
\hline & High & 257,927 & 21.9 & 212,744 & 25.2 & 470,671 & 23.2 \\
\hline \multirow[t]{4}{*}{ Education } & $\leq 9$ years & 91,259 & 7.7 & 13,631 & 1.6 & 104,890 & 5.2 \\
\hline & 10 years & 77,372 & 6.5 & 24,101 & 2.8 & 101,473 & 5.0 \\
\hline & 11 years & 98,694 & 8.3 & 32,726 & 3.9 & 131,420 & 6.5 \\
\hline & $12+$ years & 919,004 & 77.5 & 777,786 & 91.7 & $1,696,790$ & 83.4 \\
\hline \multirow[t]{3}{*}{ Cognitive index ${ }^{a}$} & $10-30$ & 193,358 & 16.4 & 94,431 & 11.2 & 287,789 & 14.2 \\
\hline & $40-70$ & 794,680 & 67.5 & 625,924 & 74.1 & $1,420,604$ & 70.2 \\
\hline & $80-90$ & 189,750 & 16.1 & 124,286 & 14.7 & 314,036 & 15.5 \\
\hline \multirow[t]{4}{*}{ BMI category $\left(\mathrm{Kg} / \mathrm{m}^{2}\right)$} & 18.5 & 161,774 & 13.6 & 118,713 & 14.0 & 280,487 & 13.8 \\
\hline & $18.5-<25$ & 866,412 & 73.0 & 615,691 & 72.6 & $1,482,103$ & 72.8 \\
\hline & $25-<30$ & 125,021 & 10.5 & 90,874 & 10.7 & 215,895 & 10.6 \\
\hline & $\geq 30$ & 33,942 & 2.9 & 22,947 & 2.7 & 56,889 & 2.8 \\
\hline \multirow[t]{4}{*}{ Height category (CDC) (percentile) } & 25th percentile & 387,793 & 32.7 & 226,199 & 26.7 & 613,992 & 30.2 \\
\hline & 25th-50th percentile & 329,644 & 27.8 & 238,839 & 28.1 & 568,483 & 27.9 \\
\hline & 50th-75th percentile & 285,662 & 24.1 & 218,594 & 25.8 & 504,256 & 24.8 \\
\hline & $>$ 75th percentile & 184,322 & 15.5 & 164,862 & 19.4 & 349,184 & 17.2 \\
\hline \multirow[t]{4}{*}{ Country of birth } & Europe & 155,845 & 13.1 & 100,030 & 11.8 & 255,875 & 12.6 \\
\hline & Asia & 25,455 & 2.1 & 13,374 & 1.6 & 38,829 & 1.9 \\
\hline & Africa & 23,734 & 2.0 & 10,887 & 1.3 & 34,621 & 1.7 \\
\hline & Israel & 981,623 & 82.7 & 724,042 & 85.3 & $1,705,665$ & 83.8 \\
\hline \multirow[t]{5}{*}{ Origin } & Europe & 542,259 & 46.1 & 401,117 & 47.6 & 943,376 & 46.7 \\
\hline & Asia & 283,819 & 24.1 & 199,373 & 23.7 & 483,192 & 23.9 \\
\hline & Africa & 279,824 & 23.8 & 190,046 & 22.5 & 469,870 & 23.3 \\
\hline & Israel & 69,762 & 5.9 & 52,322 & 6.2 & 122,084 & 6.0 \\
\hline & & Mean & SD & Mean & SD & Mean & SD \\
\hline Age at time of medical examination (years) & & 17.4 & .5 & 17.3 & .4 & 17.4 & .4 \\
\hline BMI & & 22 & 3.4 & 22 & 3.4 & 22 & 3.4 \\
\hline Height (meters) & & 174.0 & 6.8 & 162.3 & 6.1 & 169.1 & 8.7 \\
\hline
\end{tabular}

aated on a 90-point scale

The conjoined effect of birth year and origin showed that origin (North Africa and Asia) was significant only for subjects born between 1948 and 1960 (Supplemental Table 3).

\section{Discussion}

In this nationwide population-based study, we analyzed the association of the development of meningioma in subjects born between 1948 and 1991, with baseline variables obtained for the subjects at the average age of 17 years. As expected, meningiomas were found to be associated with sex (female) and taller stature. None of the other sociodemographic and medical variables assessed, including BMI and a diagnosis of asthma or diabetes at age 17 years, was associated with an increased risk of meningioma. 
Table 2 Meningioma type and rate, total and by sex

\begin{tabular}{|c|c|c|c|c|c|c|}
\hline \multirow[t]{2}{*}{ Meningioma type } & \multicolumn{2}{|l|}{ Males } & \multicolumn{2}{|l|}{ Females } & \multicolumn{2}{|l|}{ Total } \\
\hline & Number & Per 100,000 & Number & Per 100,000 & Number & Per 1000,000 \\
\hline Meningioma NOS & 71 & 0.3 & 148 & 0.9 & 219 & 0.54 \\
\hline Meningiomatosis & 0 & 0 & 1 & 0.006 & 1 & 0.002 \\
\hline Grade 1 & 62 & 0.26 & 166 & 1.01 & 228 & 0.56 \\
\hline Atypical + Anaplastic & 19 & 0.08 & 13 & 0.08 & 32 & 0.08 \\
\hline Total & 152 & 0.63 & 328 & 2.00 & 480 & 1.19 \\
\hline Person-years & $23,931,432$ & & $16,372,646$ & & $40,304,078$ & \\
\hline
\end{tabular}

NOS Not otherwise specified

It is well accepted that benign meningioma is more common in females than males, but the sex predilection disappears with the more aggressive meningiomas [2]. The female predominance might be explained by the finding that meningiomas harbor receptors for estrogen and progesterone [15].

We discovered an association between the risk of meningioma and height in men but not with BMI in men or women. The results of previous studies for these two factors were conflicting. A large Norwegian study including 1.8 million subjects found that height was associated with meningioma in both men and women but
BMI was not [5], whereas another study of postmenopausal females revealed an association of meningioma with both BMI and height [6]. A meta-analysis of 12 studies supported the correlation of BMI and meningioma. It is worth noting that the Norwegian study exceeds the meta-analysis in size and power and that in the Norwegian study a subgroup analyses for women and men, as well as different age groups, was performed without finding convincing evidence of a strong association between overweight, obesity and risk for meningioma [5]. In our study, BMI was measured when the subjects were 17 years old, much younger than the

Table 3 Univariate analysis: association of potential risk factors with diagnosis of meningioma, by sex

\begin{tabular}{|c|c|c|c|c|c|c|c|c|c|c|c|c|c|c|c|}
\hline \multirow[t]{2}{*}{ Variables } & & \multicolumn{7}{|l|}{ Males } & \multicolumn{7}{|l|}{ Females } \\
\hline & & $\bar{N}$ & Cases & Crude rate & $\mathrm{HR}$ & \multicolumn{2}{|c|}{$\begin{array}{l}\text { 95\% Cl } \\
\text { Lower Upper }\end{array}$} & $p$ & $\bar{N}$ & Cases & Crude rate & $\mathrm{HR}$ & \multicolumn{2}{|c|}{$\begin{array}{l}95 \% \mathrm{Cl} \\
\text { Lower Upper }\end{array}$} & $p$ \\
\hline \multirow[t]{5}{*}{ Height } & Percentile & & & & & & & 0.03 & & & & & & & 0.12 \\
\hline & $<25 \%$ & 387,793 & 46 & 0.58 & 1.00 & & & & 226,199 & 99 & 2.32 & 1.00 & & & \\
\hline & $25-50 \%$ & 329,644 & 34 & 0.55 & 0.91 & 0.59 & 1.42 & 0.69 & 238,839 & 91 & 1.90 & 0.77 & 0.58 & 1.02 & 0.07 \\
\hline & $50-75 \%$ & 285,662 & 40 & 0.69 & 1.24 & 0.81 & 1.89 & 0.32 & 218,594 & 69 & 1.66 & 0.73 & 0.54 & 1.00 & 0.05 \\
\hline & $>75 \%$ & 184,322 & 32 & 0.91 & 1.76 & 1.12 & 2.77 & 0.01 & 164,862 & 69 & 2.18 & 0.95 & 0.70 & 1.29 & 0.74 \\
\hline \multicolumn{2}{|l|}{ Height continuous } & & & & 1.03 & 1.01 & 1.06 & 0.02 & & & & 0.99 & 0.97 & 1.01 & 0.19 \\
\hline \multirow[t]{5}{*}{$\mathrm{BMl}$} & $\mathrm{Kg} / \mathrm{m}^{2}$ & & & & & & & 0.43 & & & & & & & 0.42 \\
\hline & 18.5 & 161,774 & 16 & 0.50 & 0.83 & 0.49 & 1.40 & 0.49 & 118,713 & 35 & 1.60 & 0.86 & 0.60 & 1.22 & 0.40 \\
\hline & $18.5-<25$ & 866,412 & 121 & 0.68 & 1.00 & & & & 615,961 & 256 & 2.11 & 1.00 & & & \\
\hline & $25-<30$ & 125,021 & 10 & 0.43 & 0.65 & 0.34 & 1.24 & 0.19 & 90,874 & 29 & 1.73 & 0.90 & 0.61 & 1.32 & 0.59 \\
\hline & $\geq 30$ & 33,942 & 4 & 0.75 & 1.46 & 0.54 & 3.96 & 0.46 & 22,947 & 8 & 2.25 & 1.60 & 0.79 & 3.23 & 0.19 \\
\hline \multirow[t]{2}{*}{ Autoimmune diseases ${ }^{a}$} & No & $1,180,535$ & 152 & 0.64 & & & & & 841,362 & 327 & 2.01 & 1.00 & & & \\
\hline & Yes & 6886 & 0 & 0.00 & & & & & 7132 & 1 & 1.07 & 0.90 & 0.13 & 6.44 & 0.92 \\
\hline \multirow[t]{2}{*}{ Allergic diseases $^{b}$} & No & $1,050,545$ & 144 & 0.66 & 1.00 & & & & 772,629 & 307 & 2.02 & 1.00 & & & \\
\hline & Yes & 136,876 & 8 & 0.36 & 0.78 & 0.38 & 1.60 & 0.50 & 75,865 & 21 & 1.75 & 1.29 & 0.83 & 2.01 & 0.26 \\
\hline \multirow[t]{2}{*}{ Asthma } & No & $1,099,711$ & 148 & 0.66 & 1.00 & & & & 803,877 & 314 & 2.01 & 1.00 & & & \\
\hline & Yes & 87,710 & 4 & 0.27 & 0.59 & 0.22 & 1.59 & 0.29 & 44,617 & 14 & 1.92 & 1.42 & 0.83 & 2.43 & 0.20 \\
\hline \multirow[t]{2}{*}{ Diabetes } & No & $1,186,027$ & 152 & 0.64 & & & & & 847,707 & 328 & 2.00 & & & & \\
\hline & Yes & 1394 & 0 & 0.00 & & & & & 787 & 0 & 0.00 & & & & \\
\hline
\end{tabular}

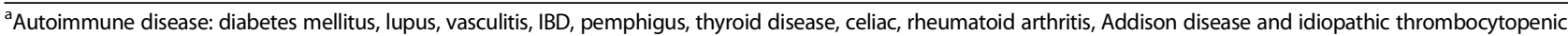
purpura

${ }^{\mathrm{b}}$ Allergic disease including asthma, urticaria, eczema, allergic rhinitis, atopic dermatitis, allergic conjunctivitis, and anaphylaxis 


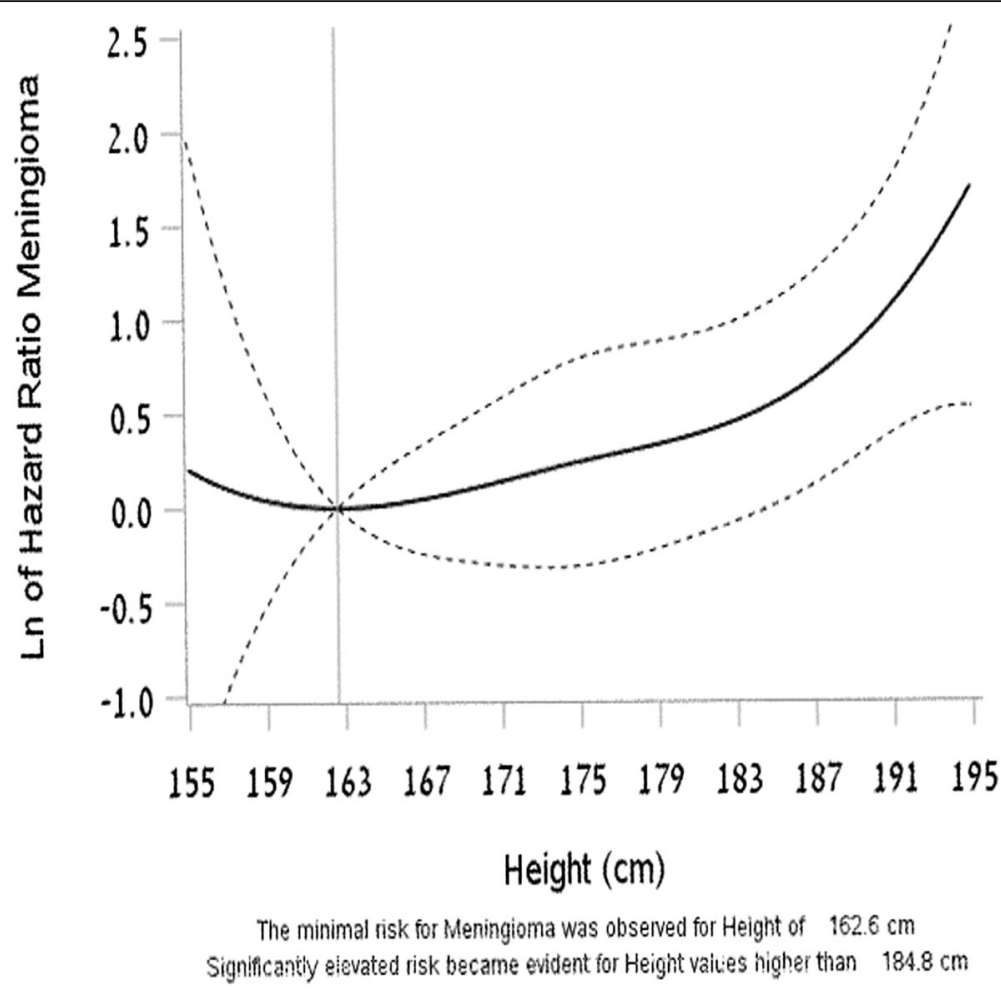

Fig. 2 Spline analysis in the men group showing the minimum risk for meningioma at a height of $1.62 \mathrm{~m}$ and a statistically significant increase in the risk for meningioma at heights taller than $1.85 \mathrm{~m}$

studies included in the metanalysis, which might explain the discordant results [8].

Height has been associated with different types of cancer (melanoma, thyroid, testis, breast, and lymphoma). Suggested mechanism for the greater risk of meningioma in taller people is their higher levels of circulating insulin-like growth factors (IGFs), which may influence cell proliferation and tumor growth [16]. Moreover, overexpression of IGF-I and IGF-II mRNA transcripts has been demonstrated in meningioma [17]. Circulating levels of IGFs are highest during puberty. They decrease rapidly in the third decade of life in the general population but seem to stay consistently higher in taller adults [18]. It is not clear why this association was evident only in males in our study, maybe in women the influence of the hormonal status blurred the influence of the height.

Several earlier studies reported an inverse association between a history of allergic diseases (including asthma) and meningioma $[9,10,18]$. However, this finding was not supported by others $[19,20]$. We failed to demonstrate an association between meningiomas and allergic diseases including asthma, urticaria, eczema, allergic rhinitis, atopic dermatitis, conjunctivitis, and anaphylaxis and allergy to bees.

Similarly, a recent study reported an inverse association between hyperglycemia and the risk of meningioma [21], whereas another found a positive association with a history of diabetes mellitus [19]. In the present study, diabetes was not associated with the risk of meningioma. This was true for other autoimmune diseases as well.

This analysis also has certain limitations. The followup period in this study was limited to 30 years such that the study population was still young when the study ended. Subsequently, the median age of those who developed meningioma in our study was younger than the median age of patients with meningioma in the general population [1]. With a more extensive follow-up, we might find more latent tumor growths that could potentially increase or shift the incidence of intracranial neoplasms. Another limitation of the study is underreporting of meningiomas that are diagnosed only according to radiographic findings (without histological findings). As it is well known that in some cases meningiomas diagnosed radiographically may just be followed by repeat scanning.

Strengths of our cohort include its prospective population-based design, large sample size, high degree of completeness of the cancer registry data throughout the study period, and the ability to carefully control for potential confounders such as exposure to radiation. It should be noted that in a study that was published recently and examined the same cohort, the median height remained almost stable during the study period (the 
median height of males increased by $3.1 \mathrm{~cm}$ and that of females remained stable) despite environmental, social and nutritional changes [22].

\section{Conclusion}

This large population-based study showed that sex (female) and tall stature in adolescent males was associated with an increased risk of meningioma in adulthood.

\section{Supplementary information}

Supplementary information accompanies this paper at https://doi.org/10. 1186/s12885-020-07292-4.

\section{Additional file 1: Supplementary Table 1. Medical history}

characteristics of the study population.

Additional file 2: Supplementary Table 2. Univariate analysis: association of potential risk factors with diagnosis of meningioma, by sex.

Additional file 3: Supplementary Table 3. Interaction between birth period and origin, whole population adjusted for sex

\section{Abbreviations}

CNS: Central nervous system; BMI: Body mass index; FCC: Functional Classification; INCR: Israel National Cancer Registry; ICD-O: International Classification of Diseases for Oncology; SD: Standard deviation; HR: Hazard ratio; Cl: Confidence interval; IGF: Insulin-like growth factor

\section{Acknowledgments}

Not applicable.

\section{Authors' contributions}

MBZB and SYK analyzed the preliminary database, extracted the relevant information to allow hypothesis testing, and prepared the manuscript and tables. Statistical analysis and figure preparation were performed by LHK and $E D$. $H L, L K B, Y L, A H, J M$ and GT participated in the preliminary preparation and conceptual design, and revised the final manuscript. ABA, OG, AK and TS reviewed the neurological proof of concept and revised the final manuscript and supplementary materials. All authors read and approved the final manuscript.

\section{Funding}

The study was funded by the Israel Cancer Association by the Lillia and Jacob Alther donation - financial support without any role in the manuscript preparation.

\section{Availability of data and materials}

The datasets used during this study are available from the corresponding author on reasonable request.

\section{Ethics approval and consent to participate}

All procedures performed in studies involving human participants were in accordance with the ethical standards of the institutional and/or national research committee and with the 1964 Helsinki declaration and its later amendments or comparable ethical standards. The study was approved by the IDF (Israel Defense Forces) Medical Corps Institutional Review Board, which waived the requirement for informed consent because the data used were obtained from medical records without patient participation (reference number: 1431-2014)

\section{Consent for publication}

Not applicable.

\section{Competing interests}

The authors declare that they have no financial or non-financial competing interests.

\section{Author details}

${ }^{1}$ Neuro-Oncology Unit, Davidoff Cancer Center, Rabin Medical Center Beilinson Hospital, Petach Tikva, Israel. ²Department of Gastroenterology, Hadassah University Hospital - Ein Kerem, Jerusalem, Israel. ${ }^{3}$ Sackler Faculty of Medicine, Tel Aviv University, Tel Aviv, Israel. ${ }^{4}$ Braun School of Public Health and Community Medicine, Hadassah University Hospital - Ein Kerem, Jerusalem, Israel. ${ }^{5}$ Israel Center for Disease Control, Israel Ministry of Health, Ramat Gan, Israel. '5chool of Public Health, University of Haifa, Haifa, Israel. ${ }^{7}$ Department of Neurosurgery, Rabin Medical Center - Beilinson Hospital, Petach Tikva, Israel. ${ }^{8}$ Medical Corps, Israel Defense Forces,and Department of Military Medicine, Hebrew University of Jerusalem, Faculty of Medicine, Jerusalem, Israel. ${ }^{9}$ Institute of Endocrinology and Talpiot Medical Leadership Program,Sheba Medical Center, Tel Hashomer, Israel.

Received: 23 April 2020 Accepted: 11 August 2020

Published online: 20 August 2020

\section{References}

1. Ostrom QT, Gittleman H, Fulop J, Liu M, Blanda R, Kromer C, Wolinsky Y, Kruchko C, Barnholtz-Sloan JS. CBTRUS statistical report: primary brain and central nervous system tumors diagnosed in the United States in 20082012. Neuro-Oncology. 2015;17(Suppl 4):iv1-iv62. https://doi.org/10.1093/ neuonc/nov189.

2. Claus EB, Bondy ML, Schildkraut JM, Wiemels JL, Wrensch M, Black PM. Epidemiology of intracranial meningioma. Neurosurgery. 2005;57:1088-95. https://doi.org/10.1227/01.neu.0000188281.91351.b9.

3. Braganza MZ, Kitahara CM, Berrington de González A, Inskip PD, Johnson KJ, Rajaraman P. lonizing radiation and the risk of brain and central nervous system tumors: a systematic review. Neuro-Oncology. 2012;14:1316-24. https://doi.org/10.1093/neuonc/nos208.

4. Modan B, Baidatz D, Mart H, Steinitz R, Levin SG. Radiation-induced head and neck tumours. Lancet. 1974;1:277-9. https://doi.org/10.1016/s01406736(74)92592-6.

5. Wiedmann MKH, Brunborg C, Di leva A, Lindemann K, Johannesen TB, Vatten L, Helseth E, Zwart JA. Overweight, obesity and height as risk factors for meningioma, glioma, pituitary adenoma and nerve sheath tumor: a large population-based prospective cohort study. Acta Oncol. 2017;56:13029. https://doi.org/10.1080/0284186X.2017.1330554.

6. Johnson DR, Olson JE, Vierkant RA, Hammack JE, Wang AH, Folsom AR, Virnig BA, Cerhan JR. Risk factors for meningioma in postmenopausal women: results from the lowa Women's health study. Neuro-Oncology. 2011;13:1011-9. https://doi.org/10.1093/neuonc/nor081.

7. Michaud DS, Bové G, Gallo V, Schlehofer B, Tjønneland A, Olsen A, Overvad K, Dahm CC, Teucher B, Boeing H, Steffen A, Trichopoulou A, Bamia C, Kyrozis A, Sacerdote C, Agnoli C, Palli D, Tumino R, Mattiello A, Bueno-deMesquita HB, Peeters PH, May AM, Barricarte A, Chirlaque MD, Dorronsoro M, José Sánchez M, Rodríguez L, Duell EJ, Hallmans G, Melin BS, Manjer J, Borgquist S, Khaw KT, Wareham N, Allen NE, Travis RC, Romieu I, Vineis P, Riboli E. Anthropometric measures, physical activity, and risk of glioma and meningioma in a large prospective cohort study. E Cancer Prev Res (Phila). 2011;4:1385-92. https://doi.org/10.1158/1940-6207.CAPR-11-0014..

8. Niedermaier T, Behrens G, Schmid D, Schlecht I, Fischer B, Leitzmann MF. Body mass index, physical activity, and risk of adult meningioma and glioma: a meta-analysis. Neurology. 2015;85:1342-50. https://doi.org/10. 1212/WNL.0000000000002020.

9. Brenner AV, Linet MS, Fine HA, Shapiro WR, Selker RG, Black PM, Inskip PD History of allergies and autoimmune diseases and risk of brain tumors in adults. Int J Cancer. 2002;99:252-9. https://doi.org/10.1002/ijc.10320.

10. Wang M, Chen C, Qu J, Xu T, Lu Y, Chen J, Wu S. Inverse association between eczema and meningioma: a meta-analysis. Cancer Causes Control. 2011;22:1355-63. https://doi.org/10.1007/s10552-011-9808-6.

11. Gal R. The selection, classification and placement process, in a portrait of the Israeli soldier. Westport, CT: Greenwood Press; 1986. p. 76-96.

12. Yust-Katz S, Bar Oz A, Derazne E, Katz LH, Levine $H$, Keinan-Boker L, Amiel A, Kanner A, Laviv Y, Honig A, Shelef I, Siegal T, Twig G, Kark J. Echoes from the past- changing associations between brain tumors and ethnicity. J Neurol Sci. 2019;408:116552. https://doi.org/10.1016/j.jns.2019.116552 [Epub ahead of print].

13. Israel Central Bureau of Statistics. Characterization and classification of local authorities by the socio-economic level of the population. Jerusalem: Israel central Bureau of Statistics; 2006. 
14. Twig G, Gluzman I, Tirosh A, Gerstein HC, Yaniv G, Afek A, Derazne E, Tzur D, Karasik A, Gordon B, Fruchter E, Lubin G, Rudich A, Cukierman-Yaffe T. Cognitive function and the risk for diabetes among young men. Diabetes Care. 2014 Nov;37(11):2982-8. https://doi.org/10.2337/dc14-0715.

15. Guevara P, Escobar-Arriaga E, Saavedra-Perez D, Martinez-Rumayor A, FloresEstrada D, Rembao D, Calderon A, Sotelo J, Arrieta O. Angiogenesis and expression of estrogen and progesterone receptors as predictive factors for recurrence of meningioma. J Neuro-Oncol. 2010;98:379-84. https://doi.org/ 10.1007/s11060-017-2662-y.

16. Gunnell D, Oliver SE, Donovan JL, Peters TJ, Gillatt D, Persad R, Hamdy FC, Meal DE, Holly JMP. Do height-related variations in insulin-like growth factors underlie the associations of stature with chronic diseases? I Clin Endocrinol Metab. 2004;81:213-8. https://doi.org/10.1210/jc.2003-030507.

17. Zumkeller W, Westphal M. The IGF/IGFBP system in CNS malignancy. Mol Pathol. 2001;54:227-9.

18. Crowe FL, Key TJ, Allen NE, et al. A cross-sectional analysis of the associations between adult height, BMI and serum concentrations of IGF-I and IGFBP-1 -2 and -3 in the European prospective investigation into cancer and nutrition (EPIC). Ann Hum Biol. 2011;38:194-202. https://doi.org/ 10.3109/03014460.2010.507221.

19. Berg-Beckhoff G, Schüz J, Blettner M, Münster E, Schlaefer K, Wahrendorf J, Schlehofer B. History of allergic disease and epilepsy and risk of glioma and meningioma (INTERPHONE study group, Germany). Eur J Epidemiol. 2009;24: 433-40. https://doi.org/10.1007/s10654-009-9355-6.

20. Schneider B, Pülhorn H, Röhrig B, Rainov NG. Predisposing conditions and risk factors for development of symptomatic meningioma in adults. Cancer Detect Prev. 2005;29:440-7. https://doi.org/10.1016/j.cdp.2005.07.002.

21. Linos E, Raine T, Alonso A, Michaud D. Atopy and risk of brain tumors: a meta-analysis. J Natl Cancer Inst. 2007;99:1544-50. https://doi.org/10.1093/ jnci/djm170.

22. Bernardo BM, Orellana RC, Weisband YL, Hammar N, Walldius G, Malmstrom $H$, Ahlbom A, Feychting M, Schwartzbaum J. Association between prediagnostic glucose, triglycerides, cholesterol and meningioma, and reverse causality. Br J Cancer. 2016;115:108-14. https://doi.org/10.1038/bjc. 2016.157.

\section{Publisher's Note}

Springer Nature remains neutral with regard to jurisdictional claims in published maps and institutional affiliations.

Ready to submit your research? Choose BMC and benefit from:

- fast, convenient online submission

- thorough peer review by experienced researchers in your field

- rapid publication on acceptance

- support for research data, including large and complex data types

- gold Open Access which fosters wider collaboration and increased citations

- maximum visibility for your research: over $100 \mathrm{M}$ website views per year

At BMC, research is always in progress.

Learn more biomedcentral.com/submissions 